\title{
THE USE OF HBIM MODELS AS A TOOL FOR DISSEMINATION AND PUBLIC USE MANAGEMENT OF HISTORICAL ARCHITECTURE: A REVIEW
}

\author{
ELENA SALVADOR GARCÍA, JORGE GARCÍA-VALLDECABRES \& MARÍA JOSÉ VIÑALS BLASCO \\ IRP/Expresión Gráfica. Universitat Politècnica de València UPV, España.
}

\begin{abstract}
Disseminating detailed and accessible information about the built heritage is fundamental to help understand the value and meaning of that heritage to society. Recent research highlights the potential of the Historic Building Information Modeling (HBIM) system for managing and disseminating heritage. However, this area is still in an early stage of development. This study aims to present a state-of-the-art review on the use of HBIM for both disseminating the value of historic architecture and managing the public use of heritage assets. The research methodology consisted of extensive bibliographic computer database searches of the study topic through specialized search tools. To this end, significant keywords have been used, such as HBIM to culture dissemination, HBIM to ICT and HBIM to public use management, among others. A total of 85 papers were initially selected. After a preliminary reading, 37 studies have been selected for this review. Later, a quantitative and critical analysis identifying the main themes and perspectives of these academic papers has been carried out. The results indicate that technological solutions have been developed to convert HBIM into models suitable for portable devices, the purpose of which is to offer virtual tours (VR) and augmented reality (AR) applications, as well as architectural heritage maintenance applications. There are also gaps in knowledge that have allowed us to establish a starting point for future research. As a conclusion, we can advance that it is essential to further the heritage interpretation of HBIM information so that the non-expert public can better understand architectural assets and their history. Also observable is the need for optimizing HBIM processes for heritage diffusion and public use management. Finally, we also noted it would be very useful to identify the most efficient way of collecting and processing data in order to achieve the best HBIM technical information for dissemination purposes.

Keywords: AR, cultural heritage, dissemination, HBIM, heritage interpretation, ICT, tourism, virtual reality.
\end{abstract}

\section{INTRODUCTION}

Building Information Modeling, technically known by its acronym (BIM), is a collaborative methodology that has improved the efficiency of work processes in the construction sector. Some international non-profit associations such as BuildingSMART seek to enhance efficiency in the construction sector through the widespread use of BIM and processes related to the life cycle of the building and by involving all the stakeholders [1]. In recent years, there has been growing interest in studying how to implement the BIM system to historic buildings, which is called HBIM (Historic BIM).

Numerous studies highlight the usefulness of HBIM for documenting and recording information about heritage as the first phase in the life cycle of historic buildings. The results of research by García-Valldecabres et al. [2] have shown that this graphic and semanticallyunified information synchronized across all disciplines clearly improves management at later phases: intervention, execution, maintenance work and dissemination to society. All these phases pursue a single common goal, asset conservation.

A great number of historic buildings are meant for public use in order to make their heritage values known to society and raise awareness for its conservation. The public use is therefore one of the fundamental tools for ensuring the conservation of historic buildings. 
Managing the public use of a monument requires: 1. Interpreting and disseminating heritage values throughout society; and 2. Managing public visits to ensure for the public's safety and satisfaction, as well as for heritage preservation.

The ICOMOS Ename Charter for the Interpretation of Cultural Heritage Sites [3] suggests interpreting heritage to increase public respect and understanding the values of cultural heritage and promote social awareness about the importance of its conservation.

Furthermore, the London Charter for the computer-based Visualisation of Cultural Heritage [4] sets guidelines and principles to ensure the necessary methodological rigour of computerbased visualization as a means of researching and communicating cultural heritage.

All this has led us to detect HBIM's potential for managing the public use of built heritage. It has also driven our interest in carrying out an extensive review of the literature to identify gaps in knowledge and propose possible future lines of research that might contribute to improving society's understanding of architectural heritage and improve the effectiveness of how public visits might be managed.

\section{REVIEW APPROACH}

For the purpose of reviewing the application of the HBIM system for public use management of heritage assets, these phases have been followed: 1. Literature Research, 2. Data Analysis, which comprises the classification of information, quantitative and qualitative analysis and 3. Results.

The issues we focused on to learn the current state of knowledge regarding the research subject were: The application of the HBIM system to 1) interpret and disseminate heritage and 2) manage public visits with HBIM.

With regard to interpretation and dissemination, we are interested in publications focusing on improving the workflow and information exchange across the disciplines responsible for documenting and intervening (e.g. architects, archaeologists, restorers, historians) and the disciplines related to interpreting and disseminating heritage (e.g. cultural managers, tourist guide-interpreters, museum curators and graphic designers). We are also interested in studies focusing on applying 3D and 4D visualization of HBIM models and combining them with VR/AR visualization and immersive technologies in order to improve understanding of architectural history by the society.

As far as managing public visits of heritage assets, we are interested in finding studies focusing on reusing information from HBIM models about the surface, sunlight, humidity and temperature in order to make it easier to develop studies on public use management, such as the recreational carrying capacity, visitor flows, hygrometric studies, etc.

\section{METHODOLOGY}

\subsection{Literature research}

To locate previous studies related to this research topic, we have examined scientific journals, conference proceedings, books and doctoral theses.

The literature review was conducted in scientific search engines such as Google Scholar, Dialnet Plus, RiuNet, Science Research, ProQuest, Scopus and Thomson Reuters Web of Science, in scientific catalogs such as OCLC Research and CrossRef, in databases such as Springer Link, SAGE journals, Taylor \& Francis Online, Science Direct, in digital libraries such as IEEE Xplore Digital Library, ASCE Library, and in scientific journals such as Virtual Archaeology Review, International Journal of Heritage in the Digital Age, Journal of Cultural 


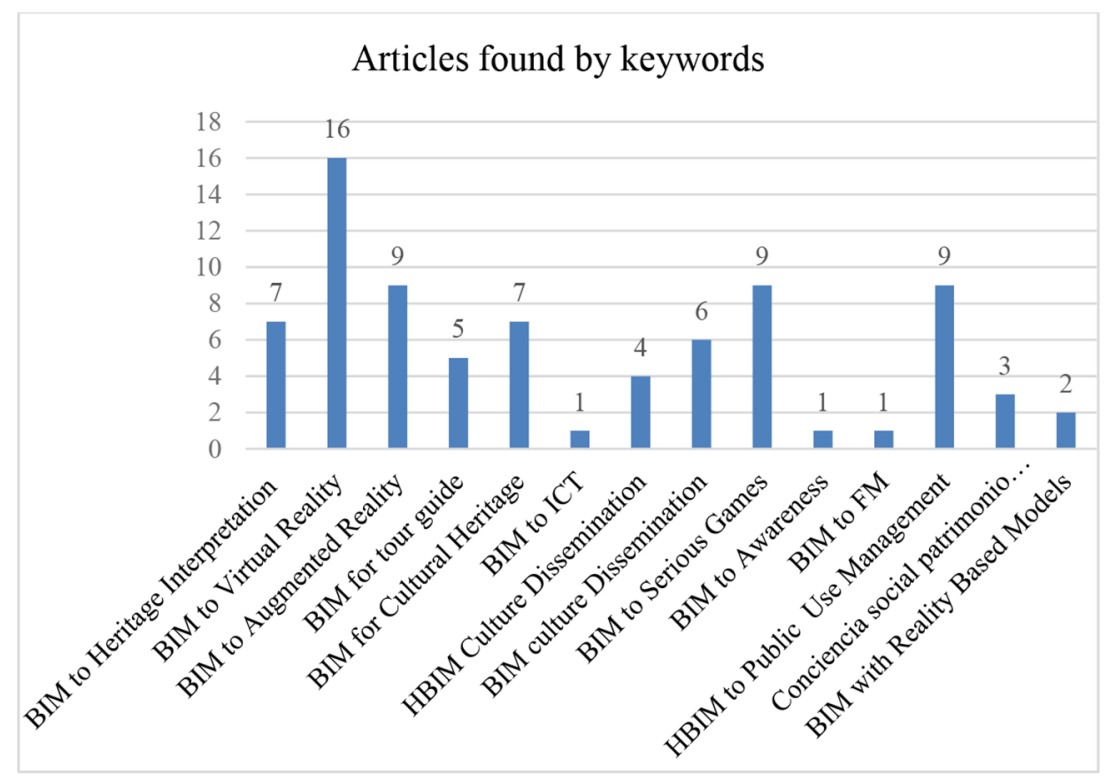

Figure 1: Articles found by keywords.

Heritage, Journal Building Research \& Information, Automation in Construction and Procedia-Social and Behavioral Sciences.

The methodology used to search for the literature was divided into two phases. In the first phase, keywords were used: BIM to Heritage Interpretation, HBIM to Virtual Reality, HBIM to Augmented Reality, HBIM to Information, Communication Technologies (ICT). To expand on the number of articles, a second phase consisted of using some keywords taken from articles from the first phase, and the word 'BIM' was used instead of 'HBIM'. The keywords used for this phase were: BIM to virtual reality, BIM to augmented reality, BIM to ICT, BIM for tour guide, BIM for cultural heritage, BIM culture dissemination, BIM to serious game, BIM to awareness, BIM to Facility Management (FM), HBIM to public use, HBIM to public use management, HBIM to recreational carrying capacity, Conciencia social patrimonio arquitectónico (Fig.1). The number of articles found was higher in the second search than it was in the first.

Literature selection was also a two-stage process. The first selection was done based on the relationship of the title with the object of research, the scientific activity of the authors, the number of times cited and the year of publication with a filter set from 2013 to the present. For the second selection, the articles were read over and those most closely related to the research topic were selected.

\section{DATA ANALYSIS}

\subsection{Classifying the information}

A total of over 85 articles were reviewed, of which: 41 were articles from scientific journals, 33 conference proceedings, 8 books and 3 doctoral theses (Fig. 2). 


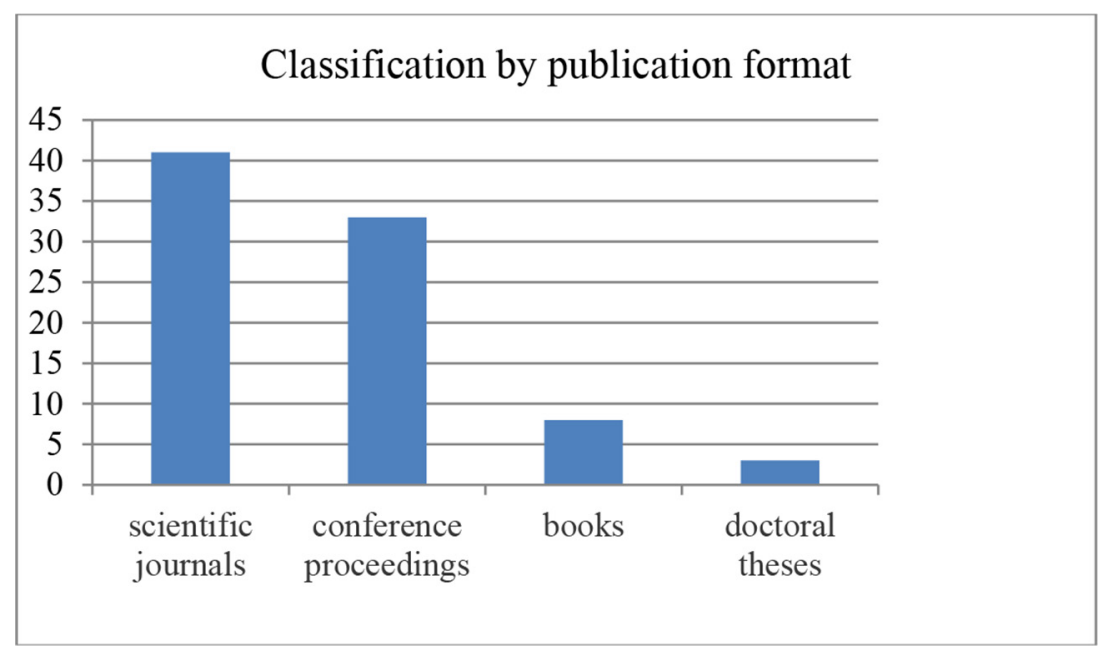

Figure 2: Classification by publication format.

To classify the information obtained, four main categories were defined according to article content. These categories were: BIM, HBIM, 3D Model. Interpreting and managing heritage.

Within the category of HBIM, the following subcategories were defined: 1. HBIM for recording, intervening, maintaining and preserving heritage; 2 . VR/AR and serious games for visualizing HBIM models; and 3. HBIM for disseminating heritage.

The BIM category was likewise divided into subcategories: 1. BIM for recording, intervening, maintaining; and 2. VR/AR and serious games for visualizing BIM models.

The article content in the 3D Model category was considered important because, even if they did not deal with Information Modeling, they were about 3D modeling, surveying, managing cultural heritage, VR/AR, serious games, Facility Management (FM), dissemination and tourism, the results of which can be extrapolated to BIM modeling.

\subsection{Quantitative analysis of the information}

Of the 85 articles found in the literature search phase, 56 were about HBIM or BIM. Of these, 34 focused on BIM and 22 on HBIM. There were 26 articles found dealing with 3D models and 4 articles focusing on interpreting and managing the public use of heritage (Fig. 3).

With regard to HBIM subcategories, 11 applied information modeling to recording, intervening, maintaining and preserving heritage, 6 applied VR/AR techniques and serious games for visualizing HBIM models, and 4 used HBIM for disseminating heritage.

Out of all the articles selected about BIM, 13 dealt with recording, intervening and maintaining buildings, and 15 with VR AR and serious games for visualizing BIM models.

\subsection{Qualitative analysis of the information}

To perform a critical analysis of the classified articles, all the abstracts and conclusions were read and the most relevant were read in their entirety. This made it possible to perform a critical analysis and objectively identify their contributions and critical gaps. Any articles that followed 


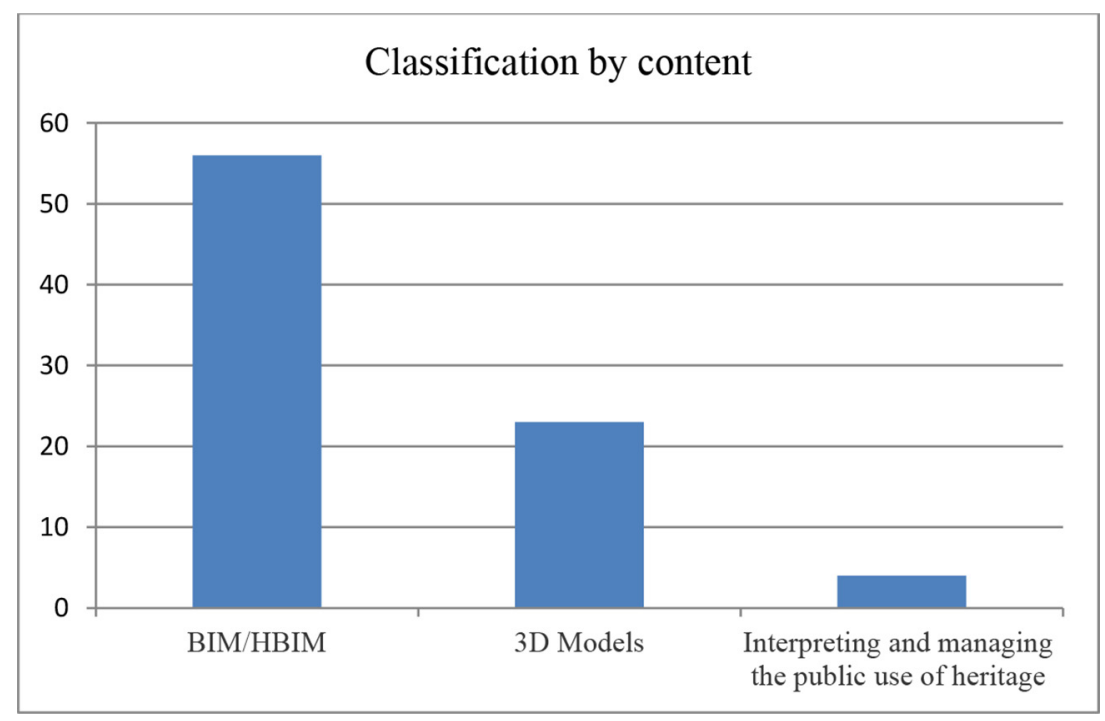

Figure 3: Classification by content.

the same line of research but with less scientific impact were discarded, as were those with the same results from the same study but appearing under different titles.

\section{RESULTS}

5.1 HBIM for recording, intervening, maintaining and preserving heritage

The BIM system was originally designed for managing construction projects, but in recent decades, methods and techniques for providing 3D digital access to architectural heritage have been studied [5]. The implementation of semantically rich 3D digital models is helping us understand heritage data beyond just its geometric characteristics [6].

Several lines of research have focused on applying BIM to the preservation of cultural heritage. Garagnani and Manferdini [7] propose parametric modeling of the complex geometry of heritage architecture onto an accurate point cloud reference through the GreenSpider plugin for Revit. Quattrini et al. [8] also studied the feasibility of modeling the complex geometry of historic architecture using BIM made from point clouds in order to obtain semantically-rich 3D models that centralize the database across disciplines. Similarly, Lo Turco et al. [9] support HBIM's potential as an operational methodology for furthering the knowledge and management of cultural heritage. García-Valldecabres et al. [2] have proposed a practical method for analyzing, dating, researching and managing heritage architecture over the course of a building's life cycle.

Oreni et al. [10] defined a three-dimensional HBIM model of a heritage building to which they have linked information about the materials, the wall stratigraphy and the geometric and historical data of the architectural elements. Those HBIM models are useful for recording, remotely accessing and sharing data to be used for preventive conservation, intervention, and maintenance of heritage.

Italy has recently been working to make a change to the construction industry through an innovative national project for creating an open source HBIM database about built heritage 
information to be shared among professionals across different disciplines. 3D models have been developed using laser scan surveys and historical archive documents.

Casu and Pisu [11] have researched the use of BIM for documenting and recreating lost heritage. To virtually recreate them, the guidelines of the London Charter have been followed: from out of historical drawings and information about similar buildings that still exist. They have created a library of virtual architectural elements and families, to which they assigned descriptive and dimensional parameters, materials, textures and information regarding the building phases.

Recent research has also been carried out on the capabilities and limitations of BIM in the archaeological field, for creating 3D architectural models integrated with databases using BIM models [5].

\subsection{VR/AR and serious games for visualizing HBIM}

Fassi et al. [12] propose using HBIM for managing maintenance activities throughout the life cycle of historic buildings. To improve visualization of the data contained in information models, they combine HBIM models with immersive visualization techniques: virtual reality (VR) and augmented reality (AR). VR immerses the user in a non-existent, virtual environment. AR, on the other hand, features virtual objects that are superimposed over real images. VR enhances the perception of reality and, for this reason, its use is on the rise for the dissemination of cultural heritage [13].

The application of VR/AR techniques in combination with HBIM aides specialized personnel carry out heritage maintenance activities and provides a tool with which the general public can take digital tours of areas that are hard to access. While using VR/AR models cannot replace actually visiting the sites, they do increase the visitors' understanding of cultural heritage while also providing support for scientific studies [12].

Osello et al. [14] present a BIM-based methodology and its interoperability for converting existing buildings into smart buildings. The combination of BIM and ICT makes it possible to manage, visualize and adapt information about existing buildings, even for children and older generations.

Pauwels et al. [15] highlight the advantages of BIM for digitizing, documenting and archiving information about heritage and considers using ICT applications to perform simulations and calculations with the stored information.

\subsection{HBIM for disseminating heritage}

In addition, 3D models for virtual visits can be generated using HBIM. In this way, modeling the historic buildings a second time for educational purposes only can be avoided [16].

Brumana et al. [17] have used the BIM system to pass on the history of built heritage for the purposes of tourism. Using laser scanner, photogrammetry, stratigraphic analysis and historical documents, they have reconstructed the most important chronological stages. They have likewise made an HBIM library for explaining and teaching about structural elements and the systems used in construction and decoration.

Cos-Gayón et al. [18] focused their research on the workflow, from the surveying of built heritage through to the HBIM, which allows users to interact with it in an immersive, virtual tour. The application's interface is highly intuitive and does not require any prior 
knowledge. Users select a route to follow and can interactively obtain information about the elements.

Barazzeti et al. [19] has developed a way for uploading HBIM models to the cloud for remotely accessing the information from mobile devices. To do so, the data obtained via the laser scanner and photogrammetry phase was processed, thus providing an accurate, reliable 3D model with a manageable file size.

Below are the most important studies on BIM that, though applied to existing buildings with no heritage value, might be extrapolated to historic buildings.

\subsection{BIM for recording, intervening and maintaining buildings}

BIM2Mar is an efficient and cost-effective solution for integrating the geometry and modeling data of newly built BIM into an MAR (mobile augmented reality) environment in such a way as to allow data to be automatically updated and accessed in real time [20].

In relation to the review on implementing BIM on existing buildings, Volk et al. [21] suggest that further research should be done on automating the processes and adapting BIM to building requirements. Gu and London [22] reached the conclusion that the factors affecting BIM adoption in the Architecture, Engineering and Construction (AEC) industry are: the needs, work processes, resources and technical tools. Eadie et al. [23] also agree that for BIM integration, it is more important to further improve on the processes than on the technology. Their studies confirm that BIM is most frequently used in the early stages of the life cycle and then sees a gradual reduction in use. They perceive, on the one hand, a lack of communication between the team and the client, and on the other, within the team itself.

\subsection{VR/AR and serious games for visualizing BIM}

Hilfert and König [24] present a workflow for simplifying and automating the import of digital BIM models of buildings originally made for the construction phase, now to be reused in VR and AR environments. This process avoids having to remodel the building a second time for visualization use only. This approach is also proposed by Shen et al. [25] and Barazzetti et al. [16] for HBIM models.

Merchant et al. [26] show that there are many examples in which VR proves beneficial to learning and how it can be applied in the field of AEC.

Mobile augmented reality applications for communicating, collaborating and teaching systems for Mechanical, Electrical and Plumbing installations (MEP) have had very good results. Wang et al. [27] propose integrating BIM and augmented reality for a more interactive architectural visualization of the building throughout the life cycle. This efficient and collaborative system provides advantages for the design team, the owner and the client.

The use of game engines in combination with BIM allows end users to participate in the design process in an interactive and collaborative way [28]. Yang [29] also proposes using serious games to raise public awareness of energy efficiency among non-expert members of society. Yan et al. [30] present a BIM_Game prototype for integrating BIM models and interactive games with an intuitive interface to enhance architectural education. Rüppel and Schatz [31] describe a serious game environment created to simulate an evacuation in case of fire. They use BIM data and include data about the materials to simulate structural damage that occurs in a fire. The VR-Lab concept uses most of the human senses and makes it possible to interact with the scene. 
Cheng et al. [32] present a theoretical model for transforming BIM models with level of detail (LoD4) into CityGML models, and then they develop a geometric transformation algorithm for reducing the file size of CityGML models.

\subsection{D models}

3D models are a useful tool for recording the historical and archaeological features of a historic building and disseminating the heritage. These models can represent the current state of the heritage through accurate surveying performed via photogrammetry and laser scanner, while also showing the stratigraphic relationships among elements and reconstructing the building sequence. Models can also be updated with information about future restorations or studies. To achieve this result, BIM and 3D models connected to a semantic database have been used. These models play an important role in interactive environments because users can actively participate, and it aides them in understanding the complexity of historic architecture and in enjoying the cultural heritage [33].

Russo et al. [34] have presented a virtual reconstruction of Villa Giulia in Etruscan times, which even included a recreation of the vegetation from that period. The scenes can be updated and reused to tell new stories. The archeologists select the content of the story to be passed on to the public during the visit.

Canciani et al. [35] have combined 3D models linked to a GIS database that can store, edit, share and display the linked data. The model contains information about the current building, about recent excavations and the hypothetical reconstruction of missing buildings. With these data, a multimedia guide has been developed for mobile applications, which receives information from the database and displays it in real time.

In addition, 3D digitalization has also become a standard tool in the field of Archeology. These digital models can be used: (1) as a graphical document, valuable information for performing an intervention or reconstructing something that has been lost; and (2) for spreading knowledge about the heritage via dissemination. This use is of special interest when the original asset is difficult to access or when visits might cause damage to the element [36].

\subsection{Interpreting and managing heritage for public use}

Technical information about heritage should be interpreted, that is to say, 'adapted' for the non-expert public. Interpreting heritage is therefore a way of communicating to provide the public with understanding and appreciation of cultural heritage [37].

Those in charge of developing programs for heritage interpretation are experts in heritage management. They use the architectural, historical and archeological information prepared by the technical team as a base, and then they adapt it. The Interpretation Program is the tool to deal with these issues [38].

In order to democratize heritage, innovative ways of managing interpretation have been developed to express the values of heritage and create experiences by decoding heritage. Taylor and Gibson [39] state that digitization reinforces the discourse of heritage.

Another tool for managing public use is the Recreational Carrying Capacity, which calculates the maximum number of people that can visit a heritage site comfortably and without negatively impacting the building [40]. 


\section{DISCUSSION AND CONCLUSIONS}

In this review, many studies have highlighted the efficiency of HBIM systems for managing historic buildings (recording, intervention planning and maintenance) throughout their life cycle. Other authors have shown the advantages of applying HBIM models for disseminating heritage in combination with immersive VR/AR visualization techniques. The graphic and semantic potential of BIM models in 3D and 4D are a great advantage for representing the constructive evolution of a building. In addition, the fact of storing information in a single place that can be synchronized and collaborated upon in real time across different disciplines means that is has many advantages for managing information about the building. However, no articles have been found that focus specifically on applying HBIM models for public use management.

Therefore, considering the results obtained in the review of the literature and also the recommendations of the international charters, can be affirmed the HBIM systems can improve interpretation, dissemination and public use management of the heritage. For these reasons, the following lines of research are proposed:

1. To harness HBIM's potential for improving communication and interpretation by developing better architectural stories. To meet this goal, we propose:

a) Generating content for interpreting and disseminating the architectural storytelling for public visits, such as the generation of a library of $4 \mathrm{D}$ historical construction systems of different types and time periods. This would help the public visualize and understand the historical construction of a specific building, in addition to being a reusable and very useful teaching tool about historic buildings with similar characteristics.

b) Furthering studies on combining HBIM models with immersive VR/AR visualization techniques to improve understanding about the hidden historical building systems and the building evolution of the asset as a whole.

2. Improve work processes across all disciplines of heritage conservation, including nontechnical disciplines of cultural management, for which we recommend:

a) Furthering social-technical aspects of the work process from the input, treatment and output of graphical and documental information contained in the HBIM models, in order to reuse it on interpretation issues (preparing the Interpretation Programme), dissemination materials (brochures, panels, multimedia content), and public use management (study of the recreational carrying capacity).

\section{ACKNOWLEDGEMENTS}

We would like to thank the reviewers of the scientific committee for their recommendations, which have undoubtedly improved the understanding of this work. This research has stemmed from out of the successful results obtained in the research project entitled 'Designing a database for managing architectural heritage information and knowledge', funded by the Ministry of Economy and Competitiveness of Spain, and developed by the article's authors.

\section{REFERENCES}

[1] Building Smart, Available at www.buildingsmart.es. accessed 16 March 2017.

[2] García-Valldecabres, J., Pellicer Armiñana, E. \& Jordán Palomar, I., BIM scientific literature review for existing buildings and theoretical method: proposal for heritage data management using HBIM. Construction Research Congress, 31 May. 1-2 Jun. San Juan de Puerto Rico, ASCE Library. pp. 2228-2238, 2016. 
[3] ICOMOS Ename Charter for the interpretation of cultural heritages sites, July 2015.

[4] The London Charter for the Use of 3D Visualisation in the Research and Communication of Cultural Heritage, First Draft 1.1, June 2006.

[5] Scianna, A., Gristina, S. \& Paliaga, S., Experimental BIM Applications in Archaeology: A Work-Flow. In: M. Ioannides, N. Magnenat-Thalmann, E. Fink, R. Žarnić, A.Y. Yen, E. Quak (eds.), Digital Heritage. Progress in Cultural Heritage: Documentation, Preservation, and Protection. EuroMed 2014. Lecture Notes in Computer Science, 8740. Springer: Cham, 2014.

[6] Saygy, G. \& Remondino, F., Management of Architectural Heritage Information in BIM and GIS; State -of-the-Art and Future Perspectives. International Journal of Heritage in the Digital Era, 2(4), pp. 695-713, 2013. https://doi.org/10.1260/2047-4970.2.4.695

[7] Garagnani, S. \& Manferdini, A.M., Parametric accuracy: Building Information Modeling process applied to the cultural heritage preservation. In 3DArch2013, Conference Proceedings of The International Archives of the Photogrammetry, Remote Sensing and Spatial Information Sciences, Trento, Italy, pp. 87-92, 2013.

[8] Quattrini, R., Malinverni, E.S., Clini, P., Nespeca, R. \& Orlietti, E., From TLS to HBIM. High quality semantically-aware 3D modeling of complex architecture. The International Archives of Photogrammetry, Remote Sensing and Spatial Information Sciences, 40(5), pp. 367-374, 2015.

https://doi.org/10.5194/isprsarchives-xl-5-w4-367-2015

[9] Lo Turco, M., Santagati, C., Parrinello, S., Valenti, G.M. \& Inzerillo, L., BIM e beni architettonici: verso una metodologia operativa per la conoscenza e la gestione del patrimonio culturale-BIM and architectural heritage: towards an operational methodology for the knowledge and the management of Cultural Heritage. Disegnare con, 9(16), pp. 161-169, 2016.

[10] Oreni, D., Brumana, R., Georgopoulos, A. \& Cuca, B., HBIM library objects for conservation and management of built heritage. International Journal of Heritage in the Digital Era, 3(2), pp. 321-334, 2014.

https://doi.org/10.1260/2047-4970.3.2.321

[11] Casu, P. \& Pisu, C., BIM application in documenting and recreating lost architectural heritage. Handbook of Research on Visual Computing and Emerging Geometrical Design Tools, 2, pp. 144-173, 2016. https://doi.org/10.4018/978-1-5225-0029-2.ch007

[12] Fassi, F., Mandelli, A., Teruggi, S., Rechichi, F., Fiorillo, F. \& Achille, C., VR for cultural heritage. In International Conference on Augmented Reality, Virtual Reality and Computer Graphics, Springer International Publishing, pp. 139-157, 2016.

[13] Guerra, J.P., Pinto, M.M. \& Beato, C., Virtual reality-shows a new vision for tourism and heritage. European Scientific Journal, ESJ, 11(9), 2015.

[14] Osello, A., Acquaviva, A., Dalmasso, D., Erba, D., Del Giudice, M., Macii, E. \& Patti, E., BIM and interoperability for cultural heritage through ICT. Handbook of Research on Emerging Digital Tools for Architectural Surveying, Modeling, and Representation, 2, p. 274, 2015.

[15] Pauwels, P., Verstraeten, R., De Meyer, R. \& Van Campenhout, J., Architectural information modelling for virtual heritage application. In International Conference on Virtual Systems and Multimedia (VSMM), Archaeolingua, pp. 18-23, 2008. 
[16] Barazzetti, L., Banfi, F., Brumana, R., Oreni, D., Previtali, M. \& Roncoroni, F., HBIM and augmented information: towards a wider user community of image and range-based reconstructions. The International Archives of Photogrammetry, Remote Sensing and Spatial Information Sciences, 40(5), pp. 35-42, 2015.

https://doi.org/10.5194/isprsarchives-xl-5-w7-35-2015

[17] Brumana, R., Oreni, D., Raimondi, A., Georgopoulos, A. \& Bregianni, A. From survey to HBIM for documentation, dissemination and management of built heritage: The case study of St. Maria in Scaria d'Intelvi. In Digital Heritage International Congress (Digital Heritage), IEEE, 1, pp. 497-504, 2013.

[18] Cos-Gayón, F., Cordón, J., Anquela, A. \& Bonet, J., Aplicaciones de la realidad virtual inmersiva en el teatro de Sagunto (Valencia, España). Congreso Internacional BIM/5 ${ }^{\circ}$ Encuentro de Usuarios BIM, pp. 138-149, 2016.

[19] Barazzetti, L., Banfi, F. \& Brumana, R., Historic BIM in the Cloud. In Euro-Mediterranean Conference, pp. 104-115, 2016.

[20] Williams G., Gheisari M., Chen P. \& Irizarry J. BIM2MAR: An efficient BIM translation to mobile augmented reality applications. Journal of Management in Engineering, 31(1), 2015.

[21] Volk, R., Stengel, J. \& Schultmann, F., Building Information Modeling (BIM) for existing buildings-Literature review and future needs. Automation in Construction, 38, pp. 109-127, 2014.

[22] Gu, N. \& London, K., Understanding and facilitating BIM adoption in D the AEC industry. Automation in Construction, 19(8), pp. 988-999, 2010.

https://doi.org/10.1016/j.autcon.2010.09.002

[23] Eadie, R., Browne, M., Odeyinka, H., McKeown, C. \& McNiff, S., BIM implementation throughout the UK construction project lifecycle: An analysis. Automation in Construction, 36, pp. 145-151, 2013.

https://doi.org/10.1016/j.autcon.2013.09.001

[24] Hilfert, T. \& König, M., Low-cost virtual reality environment for engineering and construction. Visualization in Engineering, 4(1), p. 1, 2016.

[25] Shen, Z., Jiang, L., Grosskopf, K. \& Berryman, C., Creating 3D web-based game environment using BIM models for virtual on-site visiting of building HVAC systems. In Construction Research Congress, ASCE, Reston, VA, pp. 1212-1221, 2012.

[26] Merchant, Z., Goetz, E.T., Cifuentes, L., Keeney-Kennicutt, W. \& Davis, T.J., Effectiveness of virtual reality-based instruction on students' learning outcomes in K-12 and higher education: A meta-analysis. Computers and Education, 70, pp. 29-40, 2014. https://doi.org/10.1016/j.compedu.2013.07.033

[27] Wang, J., Wang, X., Shou, W. \& Xu, B., Integrating BIM and augmented reality for interactive architectural visualisation. Construction Innovation, 14(4), pp. 453-476, 2014. https://doi.org/10.1108/ci-03-2014-0019

[28] Edwards, G., Li, H. \& Wang, B., BIM based collaborative and interactive design process using computer game engine for general end-users. Visualization in Engineering, 3, p. 4, 2015. https://doi.org/10.1186/s40327-015-0018-2

[29] Yang, L., BIM Game: a"serious game" to educate non-experts about energy related design and living (Doctoral dissertation, Massachusetts Institute of Technology), 2009. 
[30] Yan, W., Culp, C. \& Graf, R., Integrating BIM and gaming for real-time interactive architectural visualization. Automation in Construction, 20(4), pp. 446-458, 2011. https://doi.org/10.1016/j.autcon.2010.11.013

[31] Rüppel, U. \& Schatz, K., Designing a BIM-based serious game for fire safety evacuation simulations. Advanced Engineering Informatics, 25(4), pp. 600-611, 2011. https://doi.org/10.1016/j.aei.2011.08.001

[32] Cheng, J., Deng, Y. \& Du, Q., Mapping between BIM models and 3D GIS city models of different levels of detail. In 13th International Conference on Construction Applications of Virtual Reality, London, pp. 30-31, 2013.

[33] Agudo, M.D.L.Á.U., Fragero, J.I.M. \& Talaverano, R.M., Virtual models for archaeological research and 2.0 dissemination: The early medieval church of San Cebrián de Mazote (Spain). SCIRES-IT-Scientific Research and Information Technology, 6(2), pp. 93-108, 2016.

[34] Russo, A., De Lucia, M.A., Cosentino, R., Guidazzoli, A., Imboden, S., De Luca, D. \& Bellavia, G., Apa l'Etrusco sbarca a Roma e passa il testimone ad Ati. Un cortometraggio tridimensionale per raccontare il santuario di Portonaccio a Veio. Archeomatica, 6(2), 2015.

[35] Canciani, M., Chiappetta, F., Pallottino, E. \& Saccone, M., A new Gis-based map of villa Adriana, a multimedia guide for ancient paths. The International Archives of Photogrammetry, Remote Sensing and Spatial Information Sciences, 40(5), pp. 129-136, 2014. https://doi.org/10.5194/isprsarchives-xl-5-129-2014

[36] Torres, J.C., Cano, P., Melero, J., España, M. \& Moreno, J., Aplicaciones de la digitalización 3D del patrimonio. Virtual Archaeology Review, 1(1), pp. 51-54, 2010.

[37] Ham, S., Interpretación. Para marcar la diferencia intencionadamente. Sevilla, Asociación para la Interpretación del Patrimonio, 2015.

[38] Viñals M.J. \& Donat P. et al., Programa de interpretación y educación patrimonial para el Castellet de Bernabé y su entorno (Lliria, Valencia). Valencia, Universitat Politècnica de València, 2006.

[39] Taylor, J. \& Gibson, L.K., Digitisation, digital interaction and social media: embedded barriers to democratic heritage. International Journal of Heritage Studies, 23(5), pp. 408-420, 2016. https://doi.org/10.1080/13527258.2016.1171245

[40] Viñals M.J., Martínez, I., Abdennadher, A. \& Teruel, L., A recreational carring capacity assessment of the 16th century Spanish Fort of Santiago on the Island of Chikly, Tunisia Second International Conference on Defence Sites Heritage and Future, 2014, Venecia (Italia), pp. 185-196, 2014. 